\title{
Relationship Between Body Composition and Body Mass Index in Obese Women
}

\section{Mohamed Ridha Guedjati ${ }^{1 *}$, Khaoula Lachekhab ${ }^{2}$ and Abdelaziz Adjali $^{2}$}

${ }^{1}$ Professor, Department of Clinical Physiology and Metabolic Explorations and

Nutrition, Benflis Touhami University Hospital of Batna, Algeria

${ }^{2}$ Doctor, Department of Clinical Physiology and Metabolic Explorations and

Nutrition, Benflis Touhami University Hospital of Batna, Algeria

*Corresponding Author: Mohamed Ridha Guedjati, Professor, Department of

Clinical Physiology and Metabolic Explorations and Nutrition, Benflis Touhami

University Hospital of Batna, Algeria.

DOI: 10.31080/ASOR.2022.05.0430
Received: January 25, 2022

Published: February 22, 2022

(c) All rights are reserved by Mohamed Ridha

Guedjati., et al.

\begin{abstract}
Objective: The aim of our work is to study the links between anthropometric parameters and body composition obtained by bioelectric impedancemetry in case of obese women of peri- menopausal age.

Method and Materials: 154 obese women were classified according to their degree of obesity according to WHO criteria. The analysis of body composition was performed by impedancemetry. Pearson's ( $\mathrm{r}$ ) and Spearman's ( $\mathrm{r}^{2}$ ) correlations were calculated to check the relationships between age, weight, BMI, as well as total and segmental body fat composition.

Results: 154 women of mean age $40.20 \pm 13.13$ years, obese, mean BMI $38.66 \pm 6.56 \mathrm{Kg} / \mathrm{m}^{2}$ participated in our study. Impedance reduced an average total fat mass $\%$ (TFM\%) of $45.39 \pm 5.67 \%$. BMI is strongly correlated with $\mathrm{TFM} \%\left(\mathrm{r}=0.73 ; \mathrm{r}^{2}=0.82 ; \mathrm{p} \geq 0.05\right)$. For obesity stages $1-2$, weight is correlated with BMI (r-r $\left.{ }^{2}>0.40 ; \mathrm{p} \leq 0.001\right)$. Likewise, a strong correlation exists between weight and TFM in Kg $\left(r^{2}=0.82 ; p \geq 0.05\right)$. For a BMI $\geq 35 \mathrm{Kg} / \mathrm{m}^{2}$, weight is inversely correlated with age $\left[\mathrm{r}^{2} \geq(-0.36) ; \mathrm{p} \leq 0.003\right]$. The FM of the trunk $(\mathrm{Kg})$ is correlated with the weight for obesity grade $3(\mathrm{r}=0.49 ; \mathrm{p}=0.0002)$ and whatever the stage of obesity at the BMI $(r \geq$ $0.32 ; \mathrm{p} \leq 0.02)$.

Conclusion: The use of bioelectrical impedancemetry in the diagnostic management of obese people is quite useful. This tool gives us better information on the location and distribution of fatty tissue.
\end{abstract}

Keywords: Obesity; Impedancemetry; Total Fat Mass; Body Composition; BMI

\section{Introduction}

The prevalence of overweight and obesity is increasing at an alarming rate in developed and developing countries and around the world [1,2]. Numerous epidemiological studies indicate that overweight and obesity are important risk factors in the occurrence of co-morbidities such as diabetes, cardiovascular disease, cancer and early mortality [2]. This increase in prevalence, combined with these cardiometabolic risks, has become a major pub- lic health challenge [3]. The prevalence of overweight and obesity has been observed in various regions of the world. This is a major public health problem, the details of which in anthropometric, clinical and biological aspects are crucial for the development of public health strategies focused on its primary prevention and on treatment [3]. According to the World Health Organization (WHO), obesity is defined as excess of fatty tissue which can be harmful to health [4]. The incidence of obesity is growing, it is considered a global epidemic affecting both developed and developing countries 
[5]. The universally accepted index for the diagnosis and classification of obesity is the BMI (body mass index), which is expressed by the subject's weight in kg divided by the height squared in meters (weight/height ${ }^{2}$ ). [6]. In 1997, WHO adopted this index as a benchmark for overweight gradation. Overweight being defined as a BMI range of $25.0-29.9 \mathrm{~kg} / \mathrm{m}^{2}$ and obesity as a BMI $\geq 30.0 \mathrm{~kg} / \mathrm{m}^{2}$ [7]. These values were obtained on the basis of associations between BMI and mortality in European populations. These combinations therefore formed a J curve between the values of 18.5 and $25.0 \mathrm{~kg} /$ $\mathrm{m}^{2}$ [8]. Therefore, these cut- offs were used as a standard for different populations and different ethnic groups on the assumption that these different ethnic groups have an identical risk of morbidity and mortality. In addition, and in recent years, new obesity phenotypes have been described, two of which seem interesting. The metabolically healthy obese person from the English "Metabolically Healthy Obesity" or MHO $[9,10]$ and the subject with normal weight metabolically ill from the English "Normal Weight Obesity" or NWO [11]. For these two phenotypes, the BMI would no longer be adequate with the definition of obesity according to WHO criteria. It is the degree of body fat accumulation, usually expressed as a percentage that would be more appropriate for assessing the risk of developing chronic diseases in NWO subjects [12]. Although investigations are recent, it has been estimated that approximately 30 million Americans have this form (NWO) of the disorder [13,14]. However, the prevalence of these two phenotypes (MHO and NWO) is not well established and there are large variations between studies conducted to date. Variations which are attributed to aspects such as ethnic differences, the various methods used to assess body composition and the different thresholds established for a diagnosis [9].

In this regard, studies [15-17] have shown that the use of BMI is subject to imprecise interpretations in classifying obesity in different populations. In addition, the relationship between increased BMI and body fat percentage differs between different ethnic groups. Severe obesity is characterized by significant changes in body compartments compared to overweight people or those with normal weight $[18,19]$. Besides the excessive deposition of fat, there is an increase in the extracellular water (ECW) and intracellular water (ICW) ratio but also the ratio between (ECW) and total body water (TBW) $[18,20]$. These changes place several limitations on the methods commonly used to assess the body composition [19]. X-ray absorbimetry (DXA), pletysmography and in vivo neu- tron activation (IVNA) systems are no longer effective in severely obese subjects. These patients are unable to perform the maneuvers necessary to determine body fat.

However, the evaluation of body composition is important in choosing strategies to reduce body fat, but do you still need to quantify this fat mass using realistic and inexpensive means? $[21,22]$. In contrast, bioelectric impedance analysis (BIA) is a simple and reliable method for estimating fat accumulation [23]. This means makes it possible, thanks to a passage of electric current in the body, to determine the sectors which resist (hydrophobic sector) to this passage (resistance or impedances) of the sectors which conduct this current (hydrophilic sector). Bioelectrical impedance thus makes it possible to distinguish the hydrophobic sector as being essentially the fat mass of the body, whether total or segmental [24]. The applications of this technique are reported by several authors. Nyboer [25] applied four surface electrodes for bioimpedancemetric measurements to estimate the fat-free mass of the human body. Hoffer [26] presented the association between total body impedance and total body water content in reference to tritium dilution techniques. Mialich., et al. [27] examined the applications of bioimpedance analysis in assessing body composition and monitoring chronic disease through the use of a comprehensive list of equations. With regard to these readings, and in particular those relating to the limits of the use of BMI for the estimation and localization of body fat in the diagnosis and follow-up of obesity, it seems interesting to us to " study the contributions of the analysis of body composition by bioelectrical impedancemetry in case of obese subjects. Objective. Our aim is to study the links between anthropometric parameters and body composition obtained by bioelectrical impedancemetry in obese women of perimenopausal age.

\section{Method and Materials}

\section{Subjects}

One hundred and fifty-four (154) women, aged between 18 and 65 , obese (BMI $\geq 30 \mathrm{Kg} / \mathrm{m}^{2}$ ) participated in our study. They are followed at our level for the management of their obesity. They were weighed scantily clad. Those in genital activity (non-menopausal) were weighed outside the menstrual cycle. The exclusion criteria were: People whose age was under 18 or over 65 . Women who were unable to walk, amputees, and those who had water retention or carried metal objects in their bodies that could interfere with bioelectric impedance results. 


\section{Data collection}

All subjects included in the sample $(\mathrm{n}=154)$ were measured for weight and height in order to classify their degree of obesity according to BMI according to WHO criteria [4]. The height was measured with a 2-meter fixed height rod with an accuracy of 0.1 $\mathrm{cm}$ (a maximum variation of $0.5 \mathrm{~cm}$ was allowed between two measurements and the average value was calculated). Weight and body composition analysis was performed on 8-electrode impedancemetry (Tanita BC 418 MA Tokyo, Japan) Class III medical. This is a single-frequency device $(50 \mathrm{~Hz})$ whose analysis of the measured parameters are expressed in percentage and in kilograms. The parameters of this body composition analysis are total body fat (TBF) and segmental (right and left legs-arms and trunk), body water, total lean mass (TLM) and segmental (straight legs-arms and left and trunk). Muscle mass is estimated by the device and is expressed in kilograms. The device has a maximum capacity of $200 \mathrm{~kg}$ and an accuracy of $0.1 \%$. The reliability and validity of this tool in the measurement of FM as a percentage have already been verified in several ethnic groups [28,29].

For the examination of body composition, subjects were asked to wear light clothing without socks or thin stockings. Care was taken to verify that the heel was correctly aligned with the electrodes of the measurement platform. Then the subjects held retractable handles with electrodes from which electrical signals were emitted. Subjects were instructed to come after a fast of at least 8 hours, to avoid strenuous physical activity during the last 12 hours, to refrain from caffeinated drinks 24 hours before the exam, and to urinate 30 minutes before the start of the exams. All metal objects were removed from them and the measurements were taken after a 10-minute rest while lying down in an air-conditioned room with a constant temperature of $20^{\circ} \mathrm{C}$.

\section{Statistical analysis}

Continuous variables are expressed as mean values and standard deviations for normally distributed data. Categorical variables are expressed in frequencies. Pearson ( $r$ ) and Spearman $\left(r^{2}\right)$ correlations were calculated to verify the associations between age, weight, BMI, and total and segmental body composition as a function of stages of obesity. All analysis were carried out on the open access statistical analysis site BiostaTGV https://biostatgv. sentiweb.fr $/$. The level of significance was set at $\mathrm{p}<0.05$.

\section{Results}

The study was conducted on 154 women with a mean age of $40.20 \pm 13.13$ years, obese with an average BMI of $38.66 \pm 6.56$ $\mathrm{Kg} / \mathrm{m}^{2}$. The average height was $159.7 \pm 10.88 \mathrm{~cm}$ and the average weight was $98.30 \pm 19.05 \mathrm{Kg}$. Analysis of body composition by bioelectrical impedancemetry yielded an average percentage of total body fat (TBM \%) of $45.39 \pm 5.67 \%$, the equivalent of an average total fat mass in kilogram (TBM Kg) of $45.83 \pm 13.47 \mathrm{Kg}$. Total lean mass (TLM) was $56,86 \mathrm{Kg}$ while the trunk fat mass (trunk fat) was $21.62 \pm 6.08 \mathrm{Kg}$. Weight and BMI are highly correlated with TBM in Kg, in order, $r=0.85$ IC at $95 \%$ [0.86; 0.92], $r^{2}=0.92$ and $r=0.90$ IC at $95 \%[0.87 ; 0.92], r^{2}=0.90$ (Table 1 ).

\begin{tabular}{|c|c|c|c|c|c|}
\hline & \multirow[b]{2}{*}{$\begin{array}{c}\text { Average } \pm \text { standard } \\
\text { deviation }\end{array}$} & \multicolumn{2}{|c|}{ Weight $(\mathrm{Kg})(98,30 \pm 19,05)$} & \multicolumn{2}{|c|}{ BMI $\left(\mathrm{Kg} / \mathrm{m}^{2}\right)(38,66 \pm 6,56)$} \\
\hline & & $r$ & $r^{2}$ & $r$ & $r^{2}$ \\
\hline Age (years) & $40,20 \pm 13,13$ & $\begin{array}{c}(-0,0939) \quad \text { CI à95\% } \\
{[-0,2483 ; 0,0653]}\end{array}$ & $(-0,0273)$ & $\begin{array}{c}0,0218 \text { CI à } 95 \% \\
{[-0,1369 ; 0,1793]}\end{array}$ & 0,1293 \\
\hline Height $(\mathrm{cm})$ & $159,17 \pm 10,88$ & $\begin{array}{l}0,3193 \text { CI à } 95 \% \\
{[0,1697 ; 0,4545]}\end{array}$ & 0,4291 & $\begin{array}{c}0,0629 \text { CI à } 95 \% \\
{[-0,0963 ; 0,2188]}\end{array}$ & 0,0217 \\
\hline Total fat mass (\%) & $45,39 \pm 5,67$ & $\begin{array}{l}0,6486 \text { CI à } 95 \% \\
{[0,5465 ; 0,7317]}\end{array}$ & 0,7403 & $\begin{array}{c}0,72 \text { CI à 95\% } \\
{[0,634 ; 0,7884]}\end{array}$ & 0,8286 \\
\hline Total fat mass (Kg) & $45,83 \pm 13,47$ & $\begin{array}{l}0,8971 \text { CI à } 95 \% \\
{[0,8611 ; 0,9241]}\end{array}$ & 0,9169 & $\begin{array}{l}0,9044 \text { CI à } 95 \% \\
{[0,8708 ; 0,9296]}\end{array}$ & 0,9073 \\
\hline Total lean mass (Kg) & $56,86 \pm 52,91$ & $\begin{array}{c}0,3151 \text { CI à } 95 \% \\
{[0.1652 ; 0,4508]}\end{array}$ & 0,855 & $\begin{array}{l}0,2229 \text { CI à } 95 \% \\
{[0,0671 ; 0,3681]}\end{array}$ & 0,6619 \\
\hline Truncal fat mass (Kg) & $21,62 \pm 6,08$ & $\begin{array}{l}0,7947 \text { CI à } 95 \% \\
{[0,7281 ; 0,8465]}\end{array}$ & 0,8379 & $\begin{array}{l}0,7015 \text { CI à } 95 \% \\
{[0,6111 ; 0,7738]}\end{array}$ & 0,7399 \\
\hline
\end{tabular}

Table 1: Correlations between body composition and weight and BMI parameters. r: Pearson Correlation; $r^{2}$ : Spearman Correlation; CI: Confidence Index 95\%. 
The classification of our study population according to the level of obesity (WHO criteria) [4] resulted in a three-thirds distribution (Table 2).

\begin{tabular}{|l|c|c|c|c|c|c|}
\hline BMI Kg/m & Population & weight (Kg) & TBM (\%) & TBM (Kg) & TLM (Kg) & Trunk FM (Kg) \\
\hline $30 \leq \mathrm{BMI} \leq 34,9$ & $51(33)$ & $82,71 \pm 8,38$ & $40,25 \pm 5,02$ & $33,76 \pm 5,86$ & $48,23 \pm 5,16$ & $16,66 \pm 3,34$ \\
\hline $35 \leq \mathrm{BMI} \leq 39,9$ & $53(34)$ & $95,91 \pm 9,22$ & $45,80 \pm 3,26$ & $43,72 \pm 5,30$ & $52,02 \pm 5,72$ & $21,58 \pm 3,56$ \\
\hline $\mathrm{BMI} \geq 40$ & $51(33)$ & $116,73 \pm 19,14$ & $50,21 \pm 3,44$ & $60,37 \pm 11,38$ & $70,80 \pm 19,53$ & $26,72 \pm 6,10$ \\
\hline
\end{tabular}

Table 2: The distribution of population and body composition according to the grade of obesity.

$51(33 \%)$ women have grade 1 and 3 obesity with respectively a (TFM\%) of $40.25 \pm 5.02 \%$ and $50.21 \pm 3.44 \%$. We found that, depending on stages 1 and 2 of obesity, a strong correlation between weight and, TLM in Kg $\left(r=0.81, r^{2}=0.82\right)$, TLM in $\mathrm{Kg}\left(r=0.72, r^{2}=\right.$ $0.87)$ as well as the FM of the trunk in $\mathrm{Kg}\left(\mathrm{r}=0.86, \mathrm{r}^{2}=0.87\right)$ (Table 3).

\begin{tabular}{|c|c|c|c|c|}
\hline \multicolumn{5}{|c|}{ Obesity stage 1} \\
\hline & $r$ & p-value* & $r^{2}$ & p-value* \\
\hline Age years & $(-0,14)$ & NS & 0,08 & NS \\
\hline Height $\mathrm{cm}$ & 0,72 & 0,02 & 0,82 & NS \\
\hline $\mathrm{BMI} \mathrm{Kg} / \mathrm{m}^{2}$ & 0,45 & 0,0006 & 0,4 & 0,003 \\
\hline TFM \% & 0,46 & 0,0006 & 0,57 & NS \\
\hline TFM Kg & 0,81 & NS & 0,82 & NS \\
\hline TLM Kg & 0,72 & NS & 0,87 & NS \\
\hline FM Trunk Kg & 0,86 & NS & 0,87 & NS \\
\hline \multicolumn{5}{|c|}{ Obesity stage 2} \\
\hline & $\mathrm{r}$ & p-value* & $r^{2}$ & p-value* \\
\hline Age years & $(-0,38)$ & 0,003 & $(-0,39)$ & 0,003 \\
\hline Height cm & 0,91 & NS & 0,88 & NS \\
\hline $\mathrm{BMI} \mathrm{Kg} / \mathrm{m}^{2}$ & 0,42 & 0,001 & 0,47 & 0,0003 \\
\hline TFM \% & 0,04 & NS & 0,24 & NS \\
\hline TFM Kg & 0,79 & NS & 0,80 & NS \\
\hline TLM Kg & 0,82 & NS & 0,83 & NS \\
\hline FM Trunk Kg & 0,78 & NS & 0,79 & NS \\
\hline \multicolumn{5}{|c|}{ Obesity stage 3} \\
\hline & $r$ & p-value* & $r^{2}$ & p-value* \\
\hline Age years & $(-0,24)$ & NS & $(-0,36)$ & 0,009 \\
\hline Height $\mathrm{cm}$ & 0,36 & 0,008 & 0,57 & NS \\
\hline
\end{tabular}

\begin{tabular}{|c|c|c|c|c|}
\hline $\mathrm{BMI} \mathrm{Kg} / \mathrm{m}^{2}$ & 0,63 & NS & 0,65 & NS \\
\hline TFM \% & 0,37 & 0,007 & 0,4 & 0,003 \\
\hline TFM Kg & 0,74 & NS & 0,85 & NS \\
\hline TLM Kg & 0,28 & 0,04 & 0,86 & NS \\
\hline FM Trunk Kg & 0,49 & 0,0002 & 0,52 & NS \\
\hline
\end{tabular}

Table 3: The different correlations between weight and body composition depending on the stages of obesity.

r: Pearson Correlation; $r^{2}$ : Spearman Correlation; NS: Not significant;

* P-value significant for a value $<0,05$.

This correlation is not statistically significant $(\mathrm{p}>0.05)$. For obesity stages 2 and 3, weight becomes inversely correlated with age in a highly significant manner. Respectively $\left[r=(-0.38), r^{2}=\right.$ $\left.(-0.39), p=0.003 ; r=(-0.24), r^{2}=(-0.36), p=0.0009\right]$. The fat of the trunk in kg becomes significantly correlated with the total weight for obesity grade $3(r=0.49 ; p=0.0002)$. Body fat $(\mathrm{Kg})$ is significantly correlated with weight for grade 3 obesity $(r=0.49 ; \mathrm{p}=$ $0.0002)$ and regardless of the stage of obesity at BMI $(r \geq 0,32 ; p \leq$ 0.02). However, TBM in $\mathrm{kg}$ tends to lose its statistically significant correlation with the BMI $(r=0.51 ; p=0.0001)$ of grade 1 obesity for a stronger but non-significant correlation $(r=0.76$; $p>0.05)$ for obesity grades 2 and 3 (Table 4).

\begin{tabular}{|l|c|c|c|c|}
\hline \multicolumn{5}{|c|}{ Obesity stage 1 } \\
\hline & $\mathrm{r}$ & $\mathrm{p}$-value* & $\mathrm{r}^{2}$ & p-value* \\
\hline Age years & 0,27 & 0,04 & 0,39 & 0,004 \\
\hline Weight Kg & 0,45 & 0,0006 & 0,4 & 0,003 \\
\hline Height cm & $(-0,002)$ & NS & $(-0,002)$ & NS \\
\hline TFM \% & 0,16 & NS & 0,38 & 0.004 \\
\hline
\end{tabular}




\begin{tabular}{|c|c|c|c|c|}
\hline TFM Kg & 0,50 & 0,0001 & 0,52 & NS \\
\hline TLM Kg & 0,23 & NS & 0,22 & NS \\
\hline FM Trunk Kg & 0,32 & 0,02 & 0,36 & 0.008 \\
\hline \multicolumn{5}{|c|}{ Obesity stage 2} \\
\hline & $\mathrm{r}$ & p-value* & $r^{2}$ & p-value* \\
\hline Age years & $(-0,009)$ & NS & $(-0,01)$ & NS \\
\hline Height $\mathrm{cm}$ & 0,05 & NS & 0,07 & NS \\
\hline Weight Kg & 0,42 & 0,001 & 0,47 & 0,0003 \\
\hline TFM \% & 0,27 & 0,04 & 0,28 & 0,04 \\
\hline TFM Kg & 0,52 & NS & 0,52 & NS \\
\hline TLM Kg & 0,18 & NS & 0,25 & NS \\
\hline FM Trunk Kg & 0,33 & 0,01 & 0,35 & 0,009 \\
\hline \multicolumn{5}{|c|}{ Obesity stage 3} \\
\hline & $\mathrm{r}$ & p-value* & $r^{2}$ & $\mathrm{p}$-value* \\
\hline Age years & $(-0,34)$ & 0,01 & $(-0,35)$ & 0,01 \\
\hline Height $\mathrm{cm}$ & $(-0,06)$ & NS & $(-0,02)$ & NS \\
\hline Weight Kg & 0,63 & NS & 0,65 & NS \\
\hline TFM \% & 0,53 & NS & 0,5 & 0,0002 \\
\hline TFM Kg & 0,76 & NS & 0,71 & NS \\
\hline TLM Kg & 0,14 & NS & 0,62 & NS \\
\hline FM Trunk Kg & 0,34 & 0,01 & 0,23 & NS \\
\hline
\end{tabular}

Table 4: The different correlations between BMI and body composition depending on the stages of obesity.

r: Pearson Correlation; $r^{2}$ : Spearman Correlation; NS: Not significant;

* p-value significant for a value $<0,05$.

We have also seen that the TBM in (\%) follows a linear path for a BMI between 30 and $40 \mathrm{Kg} / \mathrm{m}^{2}$. This linear distribution becomes more heterogeneous beyond a BMI of $45 \mathrm{Kg} / \mathrm{m}^{2}$ (Figure 1).

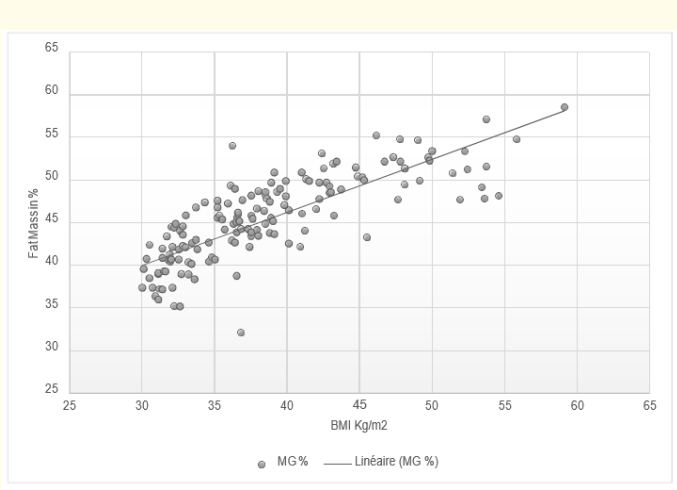

Figure 1: Change in TFM \% depending on the stage of obesity.

The percentage of TFM follows a linear pattern for BMI between 30 and $40 \mathrm{Kg} / \mathrm{m} 2$.

This TBM\% is strongly correlated with BMI $\left(r=0.72 ; r^{2}=0.82\right.$; $\mathrm{p} \geq 0.05$ ). Depending on the stage of obesity, TBM\% is significantly correlated with obesity stage 1 and $3\left(r^{2}=0.83, p=0.004 ; r^{2}=0.50\right.$, $\mathrm{p}=0.0002$ ).

\section{Discussion}

Obesity has long been described as an epidemic. This is a significant health threat. The use of BMI plays a central role in defining this excess weight. This clue seems to have a double aim. It is used both to measure a body attribute (weight for height) and to comment on this attribute (normal, overweight and obesity). It is also important to relate the degree of obesity to the risks associated with it. We thus speak of morbid obesity above $40 \mathrm{~kg} / \mathrm{m}^{2}$. This index, which is calculated using the weight/height formula 2, was proposed as a "new" index of overweight in 1972 [6]. In the mid-1990s, it became the standard method for measuring and staging obesity. At the end of the 1990s, the BMI was sufficiently documented and included in a report on anthropometry (WHO, 1995) at a consensus of this organization [7]. However, the accuracy of BMI in measuring body fat continues to be debated to this day. Although widely used as a method of measuring excessive fat tissue built-up, BMI is more of a measure of overweight- for-height than a measure of excess body weight. The BMI does not, in any case, distinguish between body fat (Fat-Mass) and non-fat (Fat-Free Mass, FFM) or lean mass. It does not take into account the distribution of fat throughout the body. So, other adiposity measurements such as waist circumference and waist-to-hip ratio and information on skinfold thickness and body fat, should also be adopted in addition to BMI to decide. On the distribution of body fat. In this regard, the analysis of body composition by impedancemetry seems to find a prominent place in the diagnosis of obesity. Physiologically, there are several models of fluid compartments that are used in the analysis of body composition. A two-compartments model (C2: fat mass and non-fat mass), a three-compartments model (C3: fat mass, total body water and dry fat mass) and the four-compartments model (C4: fat mass, total body water, minerals and residues). The traditional two-compartments model divides the body into a fatty compartment which represents fat mass (Fat Mass: FM) and non-fatty compartment (Fat Free Mass: FFM) which represents lean mass [18,19]. Some methods can be used to assess body fat, such asanthropometric, bio-impedance and plethysmography $[18,19]$. The analysis of the composition by impedance analysis of the English "Body Impedance Analysis" (BIA) estimates the body compartments (fat mass and lean mass). This estimate exploits tissue impedance based on a constant conductivity cylindrical body model [30]. It is a simple, 
inexpensive and non-invasive method [30,31]. The compartments of the body have different resistances to the passage of electric current. Bones and fats have low conductivity, while muscles and other tissues (rich in water and electrolytes) easily allow the passage of electric current. We used bioelectrical impedancemetry for the analysis of body composition in 154 obese women. This analysis seems to be interesting because it allowed us to have substantial information on the body composition of obese subjects. The use of BIA as a safe, valid and feasible tool has been accepted [32,33] and the equipment we have used has been validated in previous studies for different ethnic groups [28,29]. The use of different methods to estimate body fat in $\%$ for their validity, reliability has been discussed in various studies [34-36]. The classification of FM in\% was established by Gallagher [37]. Our work finds its originality in the fact that we have studied possible links between weight and body composition obtained by bioelectrical impedancemetry. Weight is an important semiological parameter. This is the first physical element collected in consultation and scrupulously followed by both nutritionists and their patients, especially those suffering from obesity. The interpretation of this anthropometric parameter is at the heart of the management of obesity, especially the search for possible links with the analysis of body composition and in particular with the TFM in \%, the TFM in Kg, the truncal FM. in Kg and the TLM in Kg. This is where our work finds its originality.

We found that, depending on the stage of obesity and for obesity stages 1 and 2, a strong correlation between weight and, TBM in $\mathrm{Kg}$ ( $\left.r=0.81, r^{2}=0.82\right)$, the TLM in $\mathrm{Kg}\left(r=0.72, r^{2}=0.87\right)$ as well as the trunk FM in $\mathrm{Kg}\left(\mathrm{r}=0.86, \mathrm{r}^{2}=0.87\right)$. This helps in the interpretation of nutritional status both in the diagnostic phase and in the monitoring phase of obese subjects.

More details on body weight are provided by analysing body composition using bioelectrical impedance. To our knowledge, most studies have focused much more on the links between BMI and TBM in \% [38]. Few of the studies have given a higher value to weight and even less those that have looked at the contribution of the composition of the trunk segment [39]. It was observed for an average truncal FM of $12.6 \pm 5.4 \mathrm{Kg}$, a significant correlation between the TBM in\% and the BMI but also with the truncal MG in $\mathrm{Kg}(\mathrm{r}=0.92 ; \mathrm{p}<0,01)$ [39]. In our study, we found a significant correlation ( $r=0.49 ; \mathrm{p}=0.0002)$ between the truncal fat mass in $\mathrm{kg}$ and the total weight for obesity grade 3 . It seems interesting to us to give more importance to this localization of fat mass in this obesity class. This work was carried out with women with an average age of 40 years, therefore in the perimenopausal phase. However, it is well known that this category of women becomes more exposed to the risks of cardiometabolic diseases [40]. Thus, weight has become inversely correlated with age for women whose BMI is $\geq 35 \mathrm{Kg} / \mathrm{m}^{2}\left[\mathrm{r}=(-0.38) \mathrm{r}^{2}=(-0.39) \mathrm{p}=0.003\right.$ for stage 2 obesity; $\mathrm{r}$ $=(-0.24) \mathrm{r}^{2}=(-0.36) \mathrm{p}=0.0009$ for stage 3 obesity $]$. Misra., et al. [41] found a significant association between age and the relationship BMI- TBM \% ( $r=0.89 ; \mathrm{p}<0.001)$ and BMI-TBM Kg ( $r=0.91$; $\mathrm{p}<0.001)$. In studies of age and sex, some authors have shown that there is a significant difference $(\mathrm{p}<0.01)$ in the middle age subgroup $(47.3 \pm 4.9)$ between men $(r=0.71)$ and women $(r=0.70)$ [38]. Likewise, age and sex were found to be significantly predictive variables in the regression models $(p<0.000)$, where gender contributes more to the BMI - TBM \% relationship. Women had a significantly higher average BMI than men.

Women had significantly higher total body fat than men ( $\mathrm{p}<$ 0.001). The usual pattern in most populations was that TBM \% is higher in women than in men [42], which was observed for all BMI ranges $(\mathrm{p}<0.000)$ in the study by Ranasinghe., et al. Numerous studies have confirmed the significant effect of age in the BMI-TBM $\%$ relationship [42-46]. Yusuf., et al. [47] showed that in adulthood body fat accumulation began to increase with age and tended to accumulate in certain areas of the body. BMI decreases with age over 60 , while TBM \% increases. This may be due to sarcopenia, which is explained by a gradual loss of muscle mass with age and an accumulation of body fat [48]. These changes are attributed to physical inactivity, decreased levels of certain hormones, and decreased protein synthesis that occur with aging $[48,49]$. In addition, a stabilization of this relationship between BMI and TBM in $\%$ is described in subjects of middle age (39- 45 years). For obese people, as body fat increases, extracellular fluid volume also increases. [50] Several other studies have examined extracellular water volume in relation to BMI. Brochner-Mortensen., et al. [51] compared the size and age of obese and non-obese patients, they found a higher extracellular water volume in case of obese, while Visser., et al. [52] recorded a correlation positive between BMI and increased extracellular water volume. The relationship between BMI and body composition is better documented, especially when it comes to the link with \% TBM [37-39,41]. Our results are close to those of Misra., et al. [41] with regard to the link between BMI and 
TBM in \% ( $\mathrm{r}=0.77 ; \mathrm{p}<0.001)$ but also BMI and TBM in $\mathrm{Kg}(\mathrm{r}=0$, 79; $\mathrm{p}<0.001)$. In our study, TBM \% is correlated with BMI but not significantly $\left(r=0.72 ; r^{2}=0.82 ; p \geq 0.05\right)$. Depending on the grade of obesity, we found that BMI is only weakly or moderately correlated with TBM \% (stage $1 \mathrm{r}=0.16$; stage $2 \mathrm{r}=0.27$ and stage $3 \mathrm{r}=0,53$ ).

It is therefore proposed to take the stage of obesity into account when analysing body composition. In his study Ragini found a significant correlation between BMI and TBM in \% $(r=0.92 ; p<0.01)$ [39]. Other studies $[39,41,53,54]$ have found that regardless of the stage of BMI (overweight or obesity) the link between the latter and TBM in \% is significant. However, Liang in his study [54] using the gradation of obesity, did not find a significant link $(p=0.43)$ for a BMI between 24 and $28 \mathrm{Kg} / \mathrm{m}^{2}$ and the TBM in $\mathrm{Kg}$. This reinforces our findings concerning the significant correlation between TBM in $\mathrm{Kg}$ and BMI for obesity class 1 ( $\mathrm{r}=0.50 ; \mathrm{p}=0.0001)$. It seems to us that we must take an even better interest in this parameter of body composition, especially since this correlation increases for obesity class $2(r=0.52)$ and class $3(r=0.76)$ and especially that this increase remains insignificant for these two classes of obesity ( $p$ > 0.05). Lachekhab., et al. [53] found in a study carried out on 172 overweight or obese women, that the BMI is better correlated $(\mathrm{p}<0.01)$ with the TBM in $\mathrm{kg}$ whatever the stage of the BMI (overweight $r^{2}=0.33$; stage $1 r^{2}=0.25$; stage $2 r^{2}=0.27$ and stage $3 r^{2}=$ 0.57 ) than at TBM in \%. This comforts the hypothesis of our study. BMI alone does not seem to provide accurate information about weight and the risks of being overweight. Therefore, quantification of TBM in $\mathrm{Kg}$ is substantially useful. It is better correlated with weight ( $\mathrm{r}=0.897195 \%$ CI [0.8611; 0.9241]) and BMI $(r=0.9044$ $95 \%$ CI $[0.8708 ; 0.9296])$ than the percentage of this $(r=0.6486$ $95 \%$ CI [0.5465; 0.7317]) for weight and for BMI ( $\mathrm{r}=0.7295 \% \mathrm{CI}$ [0.634; 0, 7884]). In this study [53], the correlation between BMI and TBM in $\%$ only becomes significant $(\mathrm{p}<0.01)$ from a BMI $\geq 35$ $\mathrm{kg} / \mathrm{m}^{2}$ (BMI stage $2 \mathrm{r}^{2}=0.07$; BMI stage $3 \mathrm{r}^{2}=0.23$ ). In the study by Liang., et al. [54] no link seems to exist between TBM $(23.7 \pm 3.25$ $\mathrm{Kg}$ ) and BMI (class 24 and $28 \mathrm{Kg} / \mathrm{m}^{2}$ according to the standards of the Working Group on Obesity in China. (WGOC) [55]. However, for the BMI class $\geq 28 \mathrm{Kg} / \mathrm{m}^{2}$, the link is significant ( $<<0.05$ ). We found that the TBM \% follows a linear pattern for BMIs between 30 and $40 \mathrm{Kg} / \mathrm{m}^{2}$.

This distribution becomes more and more heterogeneous for $\mathrm{BMI} \geq 45 \mathrm{Kg} / \mathrm{m}^{2}$. These results are practically similar to those ob- served in the studies by Lachekhab [53] and Abulmeaty [56]. Regardless, we found that BMI is weakly, but significantly, correlated $\left(r^{2}=0.38 ; p=0.004\right)$ with \% TBM for stage 1 obesity. This relationship becomes moderately correlated $\left(r^{2}=0.5\right)$ but highly significant $(\mathrm{p}=0.0002)$ for stage 3 obesity. We can already hypothesize that the hormonal changes during this perimenopausal phase play a role in the distribution of fat mass, which can influence the link of TBM \% with BMI described previously [39,41,53,54]. In addition, stabilization of this BMI-TBM \% relationship only occurs between the ages of 39 and 45 years [50]. Our study population has an average age below but close to this range. In addition to these hormonal changes, there are the interindividual variabilities that can be proposed to explain the dispersion of the TBM \% around an increasingly heterogeneous linear plot of the TBM $\%$ for $\mathrm{BMI} \geq 45 \mathrm{Kg} / \mathrm{m}^{2}$.

Overall, our work supports the use of bioelectric impedancemetry analysis of body composition in a clinical setting both for the diagnosis of obesity and for its monitoring. Our work has, like even, some limits. Despite all the readings we have been able to do, the BIA remains a controversial tool when it comes to the precision of its contributions in terms of body analysis. This suggests that comparative studies with other tools like DXA are desirable. Another limitation to the exclusion of males is the sample of our population. It would be useful to expand the size of the study sample to include both sexes. From this perspective, parameters such as ethnicity and larger age groups can be included. In the end, it would be preferable to introduce other clinical elements that can interfere with body composition such as skin folds, waist circumference, hip circumference and certain biological parameters such as fasting blood sugar and lipid balance, but also radiological parameters of hepatic steatosis.

\section{Conclusion}

The use of bioelectric impedancemetry in the diagnostic management of obese subjects is quite useful. This tool gives us better information on the location and distribution of fatty tissue (a determining factor in obesity). Whether expressed in (Kg) or in (\%), body composition parameters such as fat mass or non-fat mass, can be offered in addition to already known parameters such as weight and BMI.

\section{Conflict of Interest}

None. 


\section{Bibliography}

1. Abelson P. "The Obesity Epidemic". Science 304.5676 (2004): 1413-1413.

2. Haslam D and James W. "Obesity". The Lancet 366.9492 (2005): 1197-1209.

3. Kelly T., et al. "Global burden of obesity in 2005 and projections to 2030". International Journal of Obesity 32.9 (2008): 1431-1437.

4. World Health Organization. "Obesity: preventing and managing the global epidemic". Report of a WHO Consultation on Obesity. (WHO technical report series) (1998).

5. Organisation Mondiale de la Santé (OMS) | Obésité: prévention et prise en charge de l'épidémie mondiale. Rapport d'une Consultation de l'OMS, Genève (2003).

6. Quetelet LAJ. “Comparative statistics in the $19^{\text {th }}$ century. Farnborough. United Kingdom: Gregg International Publishers 1973". A treatise on man and the development of his faculties. Edinburgh. United Kingdom: William and Robert Chambers (1842).

7. World Health Organization. "Physical status: the use and interpretation of anthropometry". Report of a WHO expert committee. (WHO technical report series) (1995).

8. Javed F., et al. "Association of BMI and Cardiovascular Risk Stratification in the Elderly African-American Females". Obesity 19.6 (2010): 1182-1186.

9. Guedjati M., et al. "Profil MHO-MUHO des femmes obèses en utilisant deux types de critères de definition". Annales d'Endocrinologie 79.4 (2018): 503.

10. Guedjati M., et al. "Profils métaboliques des femmes obèses". Batna Journal of Medical Sciences bjms [En ligne] 6 (2019): 9396.

11. Lin T., et al. "Normal-weight obesity and clinical outcomes in nondiabetic chronic kidney disease patients: a cohort study". The American Journal of Clinical Nutrition 107.4 (2018): 664672.

12. Franco L., et al. "Normal-weight obesity syndrome: diagnosis, prevalence, and clinical implications". Nutrition Reviews 74.9 (2016): 558-570.
13. Oliveros E., et al. "The Concept of Normal Weight Obesity". Progress in Cardiovascular Diseases 56.4 (2014): 426-433.

14. Romero-Corral A., et al. "Normal weight obesity: a risk factor for cardiometabolic dysregulation and cardiovascular mortality". European Heart Journal 31.6 (2009): 737-746.

15. Gupta S and Kapoor S. "Optimal Cut-Off Values of Anthropometric Markers to Predict Hypertension in North Indian Population". Journal of Community Health 37.2 (2011): 441-447.

16. Gómez-Ambrosi J., et al. "Body mass index classification misses subjects with increased cardiometabolic risk factors related to elevated adiposity". International Journal of Obesity 36.2 (2011): 286-294.

17. Das S., et al. "Body composition assessment in extreme obesity and after massive weight loss induced by gastric bypass surgery". American Journal of Physiology-Endocrinology and Metabolism 284.6 (2003): E1080-E1088.

18. Das S. "Body composition measurement in severe obesity". Current Opinion in Clinical Nutrition and Metabolic Care 8.6 (2005): 602-606.

19. Sartorio A., et al. "Body water distribution in severe obesity and its assessment from eight-polar bioelectrical impedance analysis". European Journal of Clinical Nutrition 59.2 (2004): 155-160.

20. De Cleva R. "Body Composition Evaluation in Severe Obesity: A Critical Review". Advances in Obesity, Weight Management and Control 4.6 (2016).

21. Berentzen T and Sørensen T. "Effects of Intended Weight Loss on Morbidity and Mortality: Possible Explanations of Controversial Results". Nutrition Reviews 64.11 (2006): 502-507.

22. Müller M., et al. "Beyond the body mass index: tracking body composition in the pathogenesis of obesity and the metabolic syndrome". Obesity Reviews 13 (2012): 6-13.

23. Mialich M., et al. "Cutoff points of BMI for classification of nutritional status using bioelectrical impedance analysis". Journal of Electrical Bioimpedance 9.1 (2018): 24-30.

24. Khalil S., et al. "The Theory and Fundamentals of Bioimpedance Analysis in Clinical Status Monitoring and Diagnosis of Diseases". Sensors 14.6 (2014): 10895-10928.

25. Nyboer J. In: Electrical Impedance Plethysmograph. 2nd ed. Thomas C., editor. Thomas publishers Springfield, IL, USA (1970). 
26. Hoffer EC., et al. "Correlation of whole-body impedance with total body water volume". Journal of Applied Physiology 27 (1969): 531-534.

27. Mialich MS., et al. "Analysis of body composition: A critical review of the use of bioelectrical impedance analysis". International Journal of Clinical Nutrition 2 (2014): 1-10.

28. Pietrobelli A., et al. "New bioimpedance analysis system: improved phenotyping with whole-body analysis". European Journal of Clinical Nutrition 58.11 (2004): 1479-1484.

29. Sluyter J., et al. "Prediction of Fatness by Standing 8-Electrode Bioimpedance: A Multiethnic Adolescent Population". Obesity 18.1 (2010): 183-189.

30. Leal A., et al. "Bioimpedance analysis: Should it be used in morbid obesity?". American Journal of Human Biology 23.3 (2011): 420-422.

31. Coppini L., et al. "Limitations and validation of bioelectrical impedance analysis in morbidly obese patients". Current Opinion in Clinical Nutrition and Metabolic Care 8.3 (2005): 329-332.

32. Sharma A. "Obesity and cardiovascular risk". Growth Hormone and IGF Research 13 (2003): S10-S17.

33. Kyle U., et al. "Fat-free and fat mass percentiles in 5225 healthy subjects aged 15 to 98 years". Nutrition 17.7-8 (2001): 534541.

34. Berker D., et al. "Compatibility of different methods for the measurement of visceral fat in different body mass index strata". Diagnostic and Interventional Radiology 16.2 (2010): 99-105.

35. Minderico C., et al. "Usefulness of different techniques for measuring body composition changes during weight loss in overweight and obese women". British Journal of Nutrition 99.2 (2008): 432-441.

36. Fakhrawi D., et al. "Comparison of Body Composition by Bioelectrical Impedance and Dual-Energy X-Ray Absorptiometry in Overweight/Obese Postmenopausal Women". Journal of Clinical Densitometry 12.2 (2009): 238-244.

37. Gallagher D., et al. "Healthy percentage body fat ranges: an approach for developing guidelines based on body mass index". The American Journal of Clinical Nutrition 72.3 (2000): 694701.
38. Ranasinghe C., et al. "Relationship between Body mass index (BMI) and body fat percentage, estimated by bioelectrical impedance, in a group of Sri Lankan adults: a cross sectional study". BMC Public Health 13.1 (2013): 797.

39. Ragini B., et al. "Prediction of body fat using segmental body composition by bioelectrical impedance in the evaluation of obesity". ARPN Journal of Engineering and Applied Sciences 10.8 (2016): 3627-3632.

40. Binh T and Nhung B. "Prevalence and risk factors of type 2 diabetes in middle-aged women in Northern Vietnam". International Journal of Diabetes in Developing Countries 36.2 (2015): 150-157.

41. Singh A., et al. "Relationship between body mass index and percentage of body fat, estimated by bio-electrical impedance among adult females in a rural community of North India: A cross-sectional study". Journal of Postgraduate Medicine 65.3 (2019): 134.

42. Meeuwsen S., et al. "The relationship between BMI and percent body fat, measured by bioelectrical impedance, in a large adult sample is curvilinear and influenced by age and sex". Clinical Nutrition 29.5 (2010): 560-566.

43. Jackson A., et al. "The effect of sex, age and race on estimating percentage body fat from body mass index: The Heritage Family Study". International Journal of Obesity 26.6 (2010): 789-796.

44. Gallagher D., et al. "How Useful Is Body Mass Index for Comparison of Body Fatness across Age, Sex, and Ethnic Groups?". American Journal of Epidemiology 143.3 (1996): 228-239.

45. Deurenberg P., et al. "Body composition changes assessed by bioelectrical impedance measurements". The American Journal of Clinical Nutrition 49.3 (1989): 401-403.

46. Rush E., et al. "Body size, body composition and fat distribution: comparative analysis of European, Maori, Pacific Island and Asian Indian adults". British Journal of Nutrition 102.4 (2009): 632.

47. Yusuf S., et al. "Obesity and the risk of myocardial infarction in 27000 participants from 52 countries: a case- control study". The Lancet 366.9497 (2005): 1640-1649.

48. Roth SM., et al. "Strength training for the prevention and treatment of sarcopenia". The Journal of Nutrition, Health and Aging 4.3 (2000): 143-155. 
49. Roubenoff R and Hughes V. "Sarcopenia: Current Concepts". The Journals of Gerontology Series A: Biological Sciences and Medical Sciences 55.12 (2000): M716-M724.

50. Ritz P., et al. "Influence of gender and body composition on hydration and body water spaces". Clinical Nutrition 27.5 (2008): 740-746.

51. Brøchner-Mortensen J., et al. "Renal function and body composition before and after intestinal bypass operation in obese patients". Scandinavian Journal of Clinical and Laboratory Investigation 40.8 (1980): 695-702.

52. Visser F., et al. "Rise in Extracellular Fluid Volume During High Sodium Depends on BMI in Healthy Men”. Obesity 17.9 (2009): 1684-1688.

53. Guedjati M., et al. "Identification du profil bio- impédancemètrique chez des femmes obèses". Annales d'Endocrinologie 79.4 (2001): 509.

54. Liang X., et al. "Study on body composition and its correlation with obesity". Medicine 97.21 (2018): e10722.

55. Wu Y., et al. "Using appropriate pre-pregnancy body mass index cut points for obesity in the Chinese population: a retrospective cohort study". Reproductive Biology and Endocrinology 16.1 (2018).

56. Abulmeaty M., et al. "Impedancemetry vs. anthropometry in the prediction of body adiposity and obesity diagnosis". Progress in Nutrition 18.1 (2016): 39-46.

\section{Assets from publication with us}

- Prompt Acknowledgement after receiving the article

- Thorough Double blinded peer review

- Rapid Publication

- Issue of Publication Certificate

- High visibility of your Published work

Website: www.actascientific.com/

Submit Article: www.actascientific.com/submission.php

Email us: editor@actascientific.com

Contact us: +919182824667 